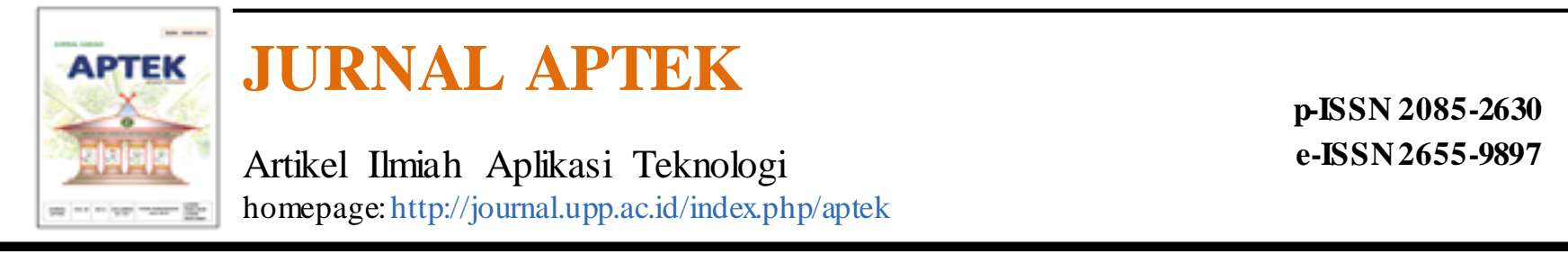

\title{
PERANCANGAN MESIN PENCACAH PELEPAH SAWIT UNTUK PAKAN TERNAK DENGAN MENGGUNAKAN METODE DFMA (DESIGN FOR MANUFACTURE AND ASSEMBLY)
}

\author{
M. Yunan Nasution ${ }^{\mathrm{a}, *}$, Saiful Anwar ${ }^{\mathrm{b}}$ \\ ${ }^{\mathrm{a} J u r u s a n}$ Teknik Pertanian, ${ }^{\mathrm{b} J u r u s a n}$ Teknik Mesin, Universitas Pasir Pengaraian, Jl. Tuanku Tambusai, Rambah,
} Pasir Pengairan, Kabupaten Rokan Hulu, Riau 28558

\section{N F O A R T I KE L}

Histori artikel:

Diajukan 08 Desember 2020

Diterima dalam bentuk revisi 13

Desember 2020

Diterima 30 Desember 2020

Tersedia Online 11 Desember 2020

\section{A B S T R A K}

Mes in pencacah pelepah sawit merupakan alat untuk mencacah pelepah sawit yang digunakan sebagai pakan temak khususnya sapi dan mengurangi limbah pelepah sawit. Tetapi, bagian yang dicacah adalah daun pelepah sawit, lebih banyak daripada pelepah sawit. Limbah kelapa sawit dihasilkan selama proses pemeliharaan tanaman (prunning), dan proses pemanenan buah, limbah juga diperoleh saat melepaskan pelepah disekitar buah dan peremajaan dengan cara menebang tanaman. Selama ini limbah pelepah sawit tidak termanfaatkan dengan baik oleh mas yarakat. Penyediaan pakan ternak merupakan suatu permasalahan yang harus segera pecahkan, seperti hamparan rumput yang sudah mulai terbatas, para warga sudah memagari pekarangan numah dan kebunnya dengan pagar, belum lagi penggunaan obat penyiang gulma (herbisida) untuk membasmi gulma(rumput-rumput) serta waktu yang dibutuhkan pada saat proses pengaritan hingga diberikan ketemak cukup lama. Penelitimerancang s ebuah mes in pencacah pelepah sawit untuk pakan ternak.

Dalam penelitian ini dirancang sebuah desain mes in pencacah daun pelepah sawit dengan menggunakan metode DFMA(Design For Manufacture and assembly). Perancangan desain mesin pencacah ini terfokus pada desain komponen dari mesin pencacah dengan menggunakan metode DFMA, dalam perancangan desin mesin pencacah daun pelapah s awit dan berdasarkan nilai evaluasi varian yang paling tinggi adalah varian nomor 2 (dua) yaitu dengan skor nilai 7.579. Setelah mendapatakan hasil skor tertinggi lalu sket, kemudian digambar menggunakan software autodesk inventor.

Kata kunci: Mesin Pencacah; Pakan Ternak; Pelepah Kelapa Sawit;

\section{A B S T RA C T}

The palm frond chopper machine is a tool for chopping oil palm fronds which are used as animal feed, especially cows and reducing palm frond waste. but the chopped part is palm fronds, more than palm fronds. palm oil waste is produced during the process of plant maintenance (prunning), and the process of harvesting the fruit, waste is also obtained when releasing the fronds around the fruit and rejuvenating by cutting the plants. The palm frond waste has not been utilized properly by the community. The provision of animal feed is a problem that must be resolved immediately, such as the limited expanse, The residents have fenced off their yards and gardens with fences, not to mention the use of herbicide to eradicate weeds (grass) and time. which is needed at the time of the curling process until it is given to the breed long enough. Then the researchers designed a palm frond chopper for animalfeed.

In this study, a design for a palm frond chopper was designed using the DFMA (Design For Manufacture and assembly) method. The design of this chopping machine design focuses on the component design of the chopper using the DFMA method, in the design of the palm leaf chopper machine and based on the evaluation value the highest variant is variant number 2 (two) with a score of 7.579. After getting the highest score, then a sketch, then drawn using the Autodesk Inventor software. 


\section{PENDAHULUAN}

Untuk memenuhi bahan pakan ternak nasional adalah dengan memanfaatkan bahan pakan lokal. Kecamatan Bangun Purba ada dua Desa, Desa Bangun Purba Timur, dan Desa Bangun Purba Barat salah satu desa yang berada di Kabupaten Rokan Hulu yang kondisi ekonomi masyarakatnya masih menengah kebawah. [11] Data dari Kantor Desa Bangun Purba Barat pada Tahun 2018, Terdapat 395 kepala keluarga (KK) yang berada di Desa Bangun Purba Barat, dengan jumlah penduduk sebanyak 1290 jiwa dan $187 \mathrm{KK}$, khusus jumlah ternak sapi sebanyak 957 Ekor, dengan luas areal desa 581,76 Ha. memiliki luas areal perkebunan kelapa sawit yang cukup luas dan didukung dengan ada kelompok tani yang mengintegrasikan dengan ternak sapi kelapa sawit untuk pakan ternak sapi. Oleh sebab itu, alat pencacah pelepah sawit adalah sebuah jaw aban yang tepat untuk menjawab pertanyaan itu, walaupun dipasaran sudah banyak yang menjual, tetapi harganya masih terlalu mahal, dan tidak ekonomis. sebagai alat pencacah bahan organik seperti dedaunan, rumput-rumputan, ranting kecil pohon dan pelepah pohon dengan cara dicacah menjadi bagian yang lebih kecil. Selain, untuk menghancurkan baik itu ranting-ranting dedaunan maupun pelepah kelapa sawit, tetapi ini khusus untuk pencacah pelapah kelapa Sawit. Perancangan Mesin Pencacah Pelepah Kelapa Sawit ini merupakan salah satu inovasi [3] Teknologi Tepat Guna(TTG) yang sangat dibutuhkan oleh masyarakat peternak sapi saat ini, untuk meningkatkan produktivitasnya. Permasalahan yang akan diteliti adalah Penyediaan pakan ternak merupakan suatu permasalahan yang harus segera dipecahkan. Salah, satu cara untuk mengatasi ketersediaan pakan tersebut adalah dengan adanya mesin pencacah pelepah kelapa sawit. Dari hasil proses pencacah pelapah kelapa sawit yang dicampur dengan unsur konsentrat merupakan salah satu jenis pakan yang di sukai ternak sapi, bahkan [4] dapat menggemukkan sapi.

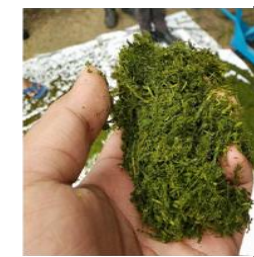

(a)

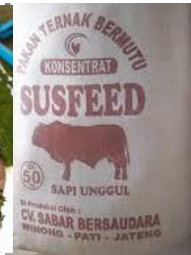

(c)

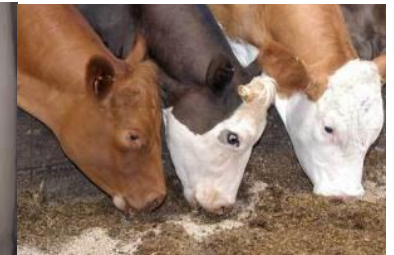

(b)
Gambar 1. (a)Hasil cacah pelepah sawit,

(b) Konsentrat, (c) Ternak sapi sedang makan hasil campuran konsentrat dan cacahan pelapah sawit.

Tujuan khususnya adalah untuk mengurangi sampah pelepah sawit yang ada dikebun sawit, selain itu tujuan khusus peneliti adalah untuk merancang desain dan nantinya dapat membuat alat pencacah pelapah kelapa sawit, yang murah dan [2] effisien menggunakan metode DFMA, jadi hanya sampai pada desain tanpa dianalisis dan menghitung poros dan lain-lain. Urgensi penelitian ini adalah dengan mengandalkan makanan rumput yang sudah terbatas, waktu yang banyak dan tenaga yang lebih besar karena harus di arit/potong lalu (dikumpulkan) dari desa lain yang cukup jauh dari lokasi perternakan. Selain itu masyarakat disini, untuk membasmi rumput atau gulma sering menggunakan racun rumput sehingga keterbatasan rumput. Dan, masyarakat disini setiap pekarangan rumah dan kebun kelapa sawit banyak yang sudah dipagari, sehingga jangkauan ternak sapi untuk mencari rumput menjadi tidak luas. Spesifikasi khusus kegiatan pascapanen ditujukan untuk mempertahankan mutu dari pelepah kelapa sawit yang terdiri dari daun agar tidak layu terlebih dahulu atau kering sehingga bisa dimanfaatkan untuk pakan ternak, dengan sentuhan teknologi mesin pencacah pelepah sawit.

\subsection{Pengertian Mesin Pencacah Pelepah Sawit}

Mesin pencacah pelepah sawit adalah mesin yang digunakan untuk mencacah pelepah sawit menjadi ukuran yang lebih kecil. Pelepah sawit yang akan dicacah adalah limbah pelepah sawit bekas yang terdapat dimana saja yang sudah di kumpulkan, biasanya pelepah sawit didapat setelah proses pemanenan buah, atau setelah melakukan pruning (pemangkasan pelepah sawit). Hal ini terpikir oleh peneliti untuk mengelola pelepah sawit bekas supaya bermanfaat, maka dirancang mesin pencacah pelepah sawit yang efesien dengan harga terjakau. Jenis pelepah sawit yang dicacah adalah pelepah sawit yang belum kering atau masih hijau

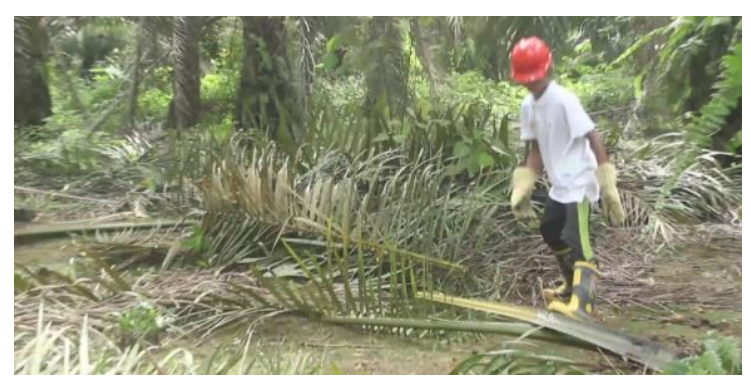

Gambar 2. Pelapah sawit seusai di pruning.

Menjalankan mesin pencacah pelepah sawit ini sangat mudah, maka menyebabkan tidak butuh tenga kerja yang banyak untuk mengoperasikanya. Dalam pencacah pelepah sawit ini pun aliran material pelepah sawit dari input sampai output harus di atur supaya lancar dengan cara memasukkan material pelepah tidak langsung banyak sekaligus melainkan secara teratur. Karena pada saat pelepah masuk kedalam ruangan pencacahan maka membutuhkan waktu untuk membuat pelepah sawit menjadi serpihan pelepah sawit. 


\subsection{Konsep Perancangan}

Dengan menggunakan konsep rancangan DFMA

Design for manufacturing and assembly (DFMA) adalah metode yang menekankan pada perkembangan pada perkembangan desain ke arah bentuk yang paling sederhana tanpa meninggalkan keinginan pasar. DFMA diartikan sebagai desain dari suatu produk atau komponen yang dapat memudahkan proses manufaktur, dan proses perakitan dengan komponen lain untuk menjadi suatu kesatuan produk. [5] DFMA apabila diartikan secara mandiri merupakan desain dari suatu produk atau komponen yang dapat memfasilitasi dan mempermudah proses perakitan dengan komponen lain. Dengan kata lain seorang desainer harus memikirkan apakah desain produk yang dibuatnya dapat memudahkan proses assembly nantinya, Bahkan dapat memberikan alternatif desain produk lainnya dalam mencapai produk berkualitas, life cycle yang rendah dan biaya produksi yang rendah.

\subsection{Perencanaan Pemilihan Bahan}

Dalam merencanakan sebuah mesin harus memperhatikan faktor keamanan baik untuk mesin itu sendiri maupun bagi operatornya Dalam pemilihan elemen-elemen dari mesin juga harus memperhatikan kekuatan bahan, safety factor, dan ketahanan dari berbagai komponen tersebut. Adapun elemen tersebut adalah mesin pencacah [6].

\subsubsection{Perancangan Mesin Pencacah (Chopper)}

Mesin pencacah (Chopper) adalah mesin yang berfungsi untuk mempercepat proses pencacahan bahan baku yang akan dijadikan pakan ternak. Mesin pencacah (Chopper) ini diharapkan dapat mengefisienkan waktu . Dengan memodernisasi peralatan produksi secara tidak langsung dapat meningkatkan efektifitas kerja. Selain berfungsi untuk pencacah pelepah kelapa sawit, mesin pencacah (chopper) dapat juga digunakan untuk mencacah berbagai macam bahan baku olahan hijau lainnya.

\subsubsection{Perancangan Poros}

Poros merupakan salah satu bagian yang terpenting dari setiap mesin. Hampir semua mesin meneruskan tenaga bersama - sama dengan putaran. Peranan utama dalam transmisi seperti itu dipegang oleh [7] poros.

\subsubsection{Perencanaan Bantalan}

Bantalan adalah elemen mesin yang menumpu poros berbeban sehingga putaran atau gerak bolak - balik dapat bekerja dengan aman, halus dan panjang umur [8] .

\subsubsection{Perancangan Puli}

Berfungsi untuk mentransmisikan daya seperti halnya sprocket rantai dan roda gigi. Puli pada umumnya dibuat dari besi cor kelabu FC 20 atau FC 30, dan adapula yang terbuat dari baja. Keuntungan menggunakan puli:

a. Puli merupakan salah satu elemen mesin yang Bidang kontak sabuk-puli luas, tegangan puli biasanya lebih kecil sehingga lebar puli bisa dikurangi.

b. Tidak menimbulkan [8] suara yang bising dan lebih tenang.

\subsubsection{Perancangan Sabuk -V}

Jarak antara dua buah poros sering tidak memungkinkan motor elektrik langsung dengan poros pencacah pelepah sawit. Dalam hal ini demikian cara mesin penggerak yang lain diterapkan dimana sebuah sabuk luwes atau rantai dibelitkan sekeliling puli atau sprocket pada poros. Sabuk atau belt terbuat dari karet dan mempunyai penampang trapezium, tenunan, teteron dan semacamnya digunakan sebagai [8] inti sabuk untuk membawa tarikan yang besar.

\subsubsection{Perancangan Pasak}

Pasak adalah suatu elemen mesin yang dipakai untuk menetapkan bagian bagian mesin seperti roda gigi, sprocket, puli, kopling pada poros, Momen diteruskan dari poros ke naf atau dari naf ke poros. Pasak pada umumnya dapat digolongkan atas beberapa macam. Menurut letaknya pada poros dapat dibedakan antara pasak pelana, pasak rata, pasak benam,dan pasak singgung yang umumnya berpenampang persegi empat [8].

\subsubsection{Perancangan Rangka}

Rangka mesin yang akan dibuat menggunakan baja karbon rendah, dan profil yang digunakan adalah profil U. Proses pembuatan rangka yaitu dengan melakukan proses pemotongan menggunakan alat cutting wheel sesuai ukuran yang telah di tentukan dalam proses perancangan, setelah itu dilakukan proses penyambungan logam dengan menggunakan las listrik. Rangka ini berfungsi untuk menumpu seluruh komponen mesin pemotong plastik menjadi satu kesatuan, selain itu rangka ini berfungsi untuk memperkokoh mesin dan [8] meredam getaran yang dihasilkan akibat proses pencacahan pelepah kelapa sawit.

\subsubsection{Perancangan Mur dan Baut}

Pemilihan mur dan baut sebagai pengikat harus dilakukan dengan teliti untuk mendapatkan ukuran yang sesuai dengan beban yang terimanya sebagai usaha untuk mencengah kecelakaan pada mesin. Mur dan baut pada alat mesin pencacah ini digunakan untuk mengikat beberapa komponen. 
Perancangan Mesin Pencancah pelepah sawit ini, bila setelah dirancang dan akan dibangun alatalat yang dibutuhkan sebagai berikut antara lain: Mesin Bubut, Mesin gerinda Tangan, Mesin Bor, dan Mesin Las.

\subsubsection{Perancangan Keberagaman Cacahan}

Setiap mesin pencacah memiliki kriteria output cacahan yang nantinyadimanfaatkan lebih lanjut, seperti digunakan sebagai pakan ternak. Pada umumnya, ukuran output cacahan yang digunakan dalam pengujian mesin pencacah (chopper) adalah $1 \mathrm{~cm}, 1 \mathrm{~cm}$ $\mathrm{x} 2,5 \mathrm{~cm}, 2,5 \mathrm{~cm} \times 5 \mathrm{~cm}$, dan $5 \mathrm{~cm}$, namun ukuran output cacahan yang digunakan sebagai kriteria keberhasilan penelitian ini adalah output cacahan pada ukuran $1 \mathrm{~cm}$ dan 1 $\mathrm{cm} \times 2,5 \mathrm{~cm}$. Cacahan pelepah sawit dengan ukuran sekitar $5 \mathrm{~cm}$ masih terbilang kasar, sehingga tidak dapat langsung diberikan kepada ternak karena akan melukai lambung ternak sapi. Selain itu, ukuran cacahan $1 \mathrm{~cm} \mathrm{x}$ $2,5 \mathrm{~cm} \mathrm{[1]}$

\section{MATERIAL DAN METODE}

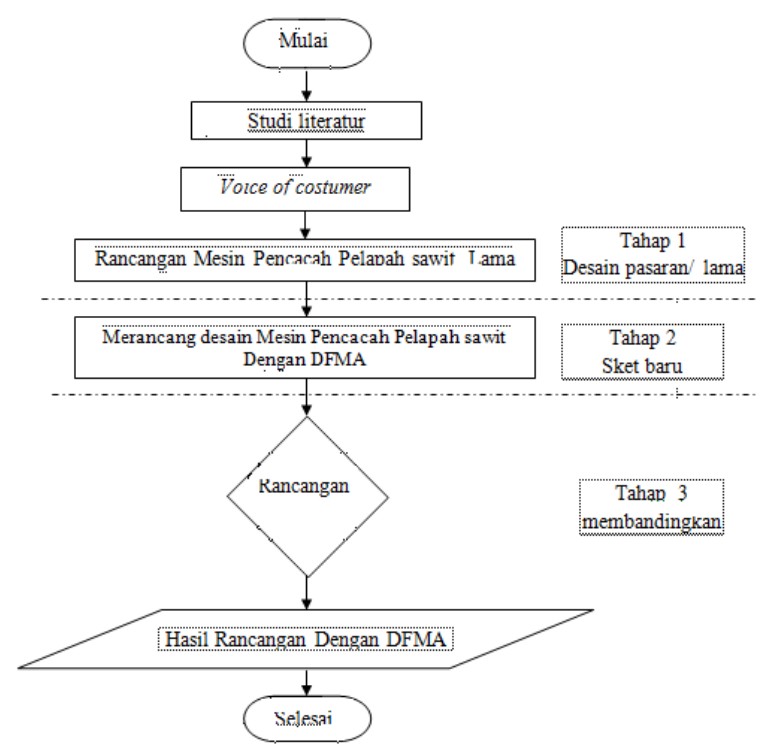

Gambar 3. Diagram Alir

1. Mulai

Sebelum memulai ke studi literatur dan lainlain. harus ditentukan terlebih dahulu langkah proses memulainya darimana.

2. Studi Literatur

Pada Studi literatur merupakan tahap pencarian data dan literatur untuk mencari sumber-sumber yang relevan yang dapat dipercaya sehingga dapat memperkuat penelitian ini.

3. Voice Of Costumer

Mengindentifikasi kebutuhan pelanggan melalui skema voice of customer. Dengan adanya hasil identifikasi kebutuhan pelanggan ini, diharapkan penelitian ini dapat melakukan perancangan yang lebih akurat.

4. Rancangan mesin pencacah pelepah sawit lama

Dengan adanya data atau tabel gambar rancangan lama, dapat mengetahui kekurangan dari rancangan lama dan membandingkan dengan rancangan baru.

5. Merancang desin mesin pencacah pelepah saw it dengan DFMA

Tahapan ini merancang desin mesin pencacah pelepah sawit yaitu dengan menggunakan metode DFMA, hasil rancangan dengan nilai tertinggi yang nantinya akan dirancang atau di sket baru.

6. Rancangan

Setelah mendapatkan hasil rancangan dengan menggunakan metode DFMA, sket baru, lalu dirancang menggunakan Software Autodesk Inventor.

7. Hasil rancangan dengan DFMA

Setelah melakukan perancagan dengan menggunakan metode DFMA dan mendesainya menggunakan software autodesk inventor.

\section{Design for Manufacture and Assembly (DFMA)}

DFMA terdiri dari design for manufacture (DFM) dan design for assembly (DFA). [5]DFM bertujuan untuk mempermudah proses manufaktur tiap komponen penyusun produk dan DFA bertujuan untuk menyederhana-kan struktur produk agar proses perakitannya menjadi lebih singkat. Kedua hal ini akan mengakibatkan berkurangnya ongkos dan waktu yang diperlukan untuk memproduksi suatu produk sehingga produk tersebut dapat dikeluarkan lebih cepat ke pasaran. Dalam siklus desain produk, DFMA terletak setelah adanya konsep desain dan sebelum proses pembuatan prototipe. Awalnya konsep desain yang ada diperbaiki strukturnya dengan metoda DFA. Kemudian setiap komponennya dianalis is dengan metoda DFM agar proses produksinya menjadi mudah.

\section{DFMA Menurut Boothroyd dan Dewhurst}

Salah satu metoda DFMA yang telah dikembangkan adalah metoda DFMA menurut Boothroyd dan Dewhurst. Menurut metoda ini, analisis DFA dilakukan dengan mengetahui proses perakitan ulang produk. Waktu yang diperlukan untuk masing-masing proses perakitan dapat diketahui dari tabel perakitan manual Boothroyd. Disamping prakiraan durasi yang diperlukan untuk merakit produk, metoda ini menilai proses perakitan produk menggunakan suatu indeks yaitu:

(Determining Overall Weighing Value/OWV)

$W R J=\frac{O W J}{V \max \sum_{i=1}^{n} W i}$ 
Komponen esensial adalah komponen yang harus dapat bergerak relatif terhadap komponen lain, atau terbuat dari material yang berbeda, atau harus terpisah agar perakitan komponen esensial lainnya tidak terhalangi. Sedangkan DFMA dapat dilakukan secara iteratif dari memilih material mentah, menentukan proses produksinya, kemudian dihitung ongkosnya untuk kemudian dioptimasi. Sebagai pembatasan masalah, pada penelitian ini hanya akan dijelaskan penerapan metoda DFMA Boothroyd dan Dewhurst pada handle produk mesin pencacah daun pelepah saw it beserta hasilnya.

\section{Identifikasi Kebutuhan}

Identifikasi kebutuhan data dan semua informasi yang berhubungan langsung dengan perancangan dan diharapkan dapat memberikan solusi akhir. Data dan semua informasi yang diperoleh dapat dikembangkan menjadi suatu dasar perancangan, karena dari data dan informasi tersebut yang menjadi acuan dalam penyusunan spesifikasi, tahap perancangan serta optimalisasi solusi proses perancangan optimasi desain mesin pencacah daun pelepah sawit. Yang harus dilakukan dalam mempersiapkan daftar spesifikasi adalah membedakan persyaratan sebagai Permintaan/Keharusan (demand) atau sebagai keinginan (Wishes). Demand adalah segala persyaratan yang harus dipenuhi dalam segala kondisi dengan kata lain apabila tidak terpenuhi, maka solusi yang tercapai tidak dapat terima. Wishes adalah persyaratan yang diinginkan dan apabila memungkinkan dapat dimasukkan melalui pertimbangan [9] .

Tabel 1. Daftar sepesifikasi Demand dan Wishes
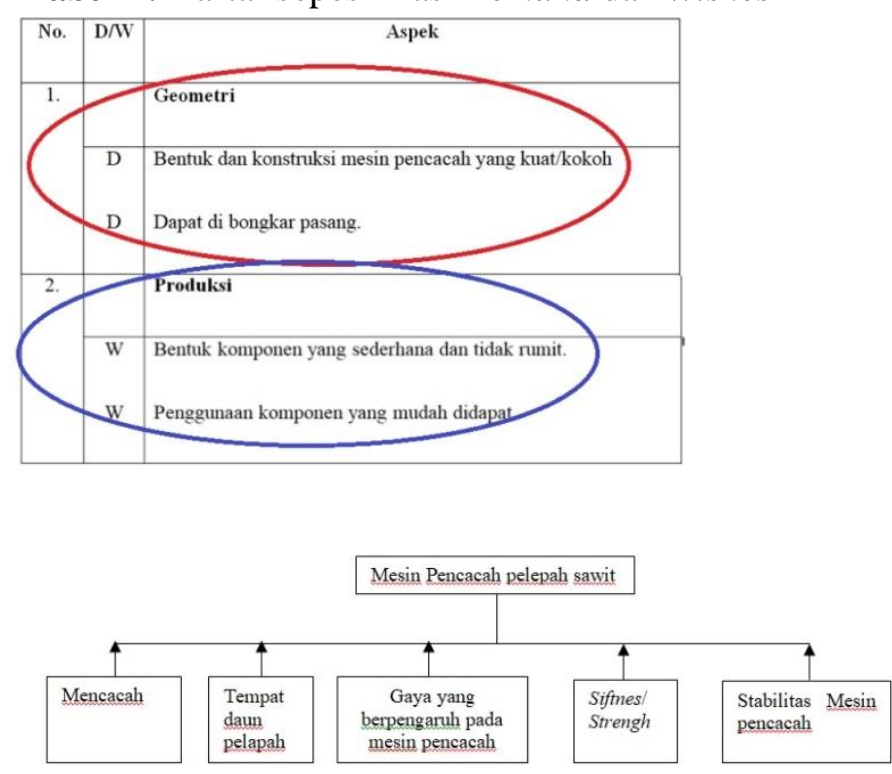

Gambar 4. Sub-Fungsi

Tabel 2. Skala Nilai Guide Line VDI 2221

\begin{tabular}{|c|c|}
\hline \multicolumn{2}{|c|}{ Skala Nilai } \\
\hline Point & Arti \\
\hline 1 & Tidak Memuaskan \\
\hline
\end{tabular}

\begin{tabular}{|l|l|}
\hline 2 & Dapat Ditolerir \\
\hline 3 & Cukup / Memadai \\
\hline 4 & Baik \\
\hline 5 & Sangat Baik \\
\hline
\end{tabular}

Dari rumus dibawah ini dapat ditentukan varian yang sesuai untuk di buat:

(Determining Overall Weighing Value/OWV),

$$
\begin{aligned}
& \text { WRJ }=\frac{O W J}{V \max \sum_{i=1}^{n} W i} \\
& \text { Varian } 1=W R J=\frac{3,08}{5 \times 11}=6,776 \\
& \text { Varian } 2=W R J=\frac{3,445}{5 \times 11}=7,579 \\
& \text { Varian } 3=W R J=\frac{3.28}{5 \times 11}=7,216
\end{aligned}
$$

Ranking 1 : rating varian ke-3 $=7,216$

Ranking 2 : rating varian ke- $2=\underline{\mathbf{7 , 5 7 9}}$

Ranking 3 : rating varian ke- $1=6,776$

Maka untuk perancangan Forklift manual, dipilih varian (V2) karena memiliki rating paling tinggi, skor yang paling tinggi yaitu $\mathbf{7 , 5 7 9}$. yang memiliki keunggulan, diantaranya:

1) Menggunakan Mesin Diesel Mesin ini mudah di operasikan dan cukup kuat bila menggunakan sebagai penc ac ahnya dari mesin diesel.

2) Menggunakan bearing/ bantalan ball bearing

Menggunakan bearing blok bearing, ada dudukanya dari bearing dan lebih kuat serta tahan lama, dikarenakan ada juga tempat pispot(gemuknya)

3) Menggunakan besi UNP

Besi UNP berbentuk persegi panjang dan untuk rangkanya di pilih besi UNP agar lebih stabil dan kokoh, mudah pada saat dibuat tempat stel baut dan mur.

\section{Kriteria Disain}

Perancangan mesin pencacah pelepah sawit harus dilakukan melalui perhitungan yang se-efisien mungkin, karena mempunyai pengaruh besar terhadap hasil produk tersebut. mesin pencacah pelepah sawit itu sendiri merupakan suatu alat yang dipakai untuk mencacah pelepah sawit untuk menjadi bahan tambah pakan ternak sapi.

Mesin pencacah pelepah sawit ini dirancang dengan bentuk konstruksi rangka yang sederhana dan kuat terhadap proses pengelasan dengan beberapa bagian utama terbuat dari bahan-bahan yang sudah tersedia di pasaran dan bahan yang digunakan merupakan bahan baku pilihan yang sangat kuat, tidak mudah korosi.

\section{Prinsip kerja Mesin Pencacah Pelepah Sawit}

Mesin pencacah pelepah saw it ini merupakan mesin pencacah yang di desain untuk mencacah 
pelepah daun sawit, dengan Alat ini menggunakan sistem manual yang mana pelepah atau daun sebelum dicacah harus masuk ke saluran masuk, begitu setelah siap dicacah melalui saluran keluar, hasil pencacahan masih dibantuk juga sama tangan yaitu hasil cacahan pelapah sawit mengguakan tangan. di operasikan dengan cara pertama mengengkol mesin diesel sampai hidup lalu menyetel gas mesin diesel sesuai dengan yang diinginkan supaya stabil, mesin ini pada saat mencacah biaya produksinya lebih murah dan effisien.

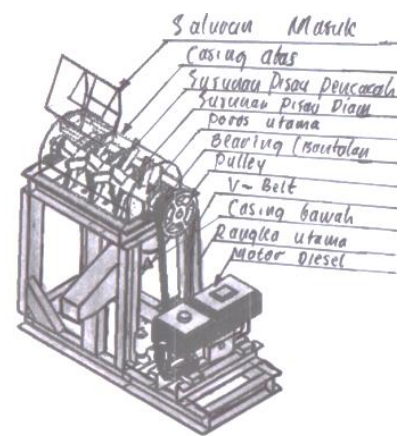

Gambar 5. Mesin pencacah dan bagian-bagianya.

\section{Morfologi Chart}

Morphological Chart adalah ringkasan dari suatu analisis perubahan bentuk secara sistematis untuk mengetahui bagaimana bentuk suatu produk dirancang, yang berisi elemen-elemen, komponenkomponen atau sub-sub solusi yang lengkap yang dapat dikombinasikan, tetapi harus membuat proposal terlebih dahulu sebelum membuat perancangan. Contoh dibawah ini diambil beberapa item, prinsip solusi sub fungsi dan cara pemilihan [10] .

Tabel 3. Kombinasi prinsip solusi sub fungsi

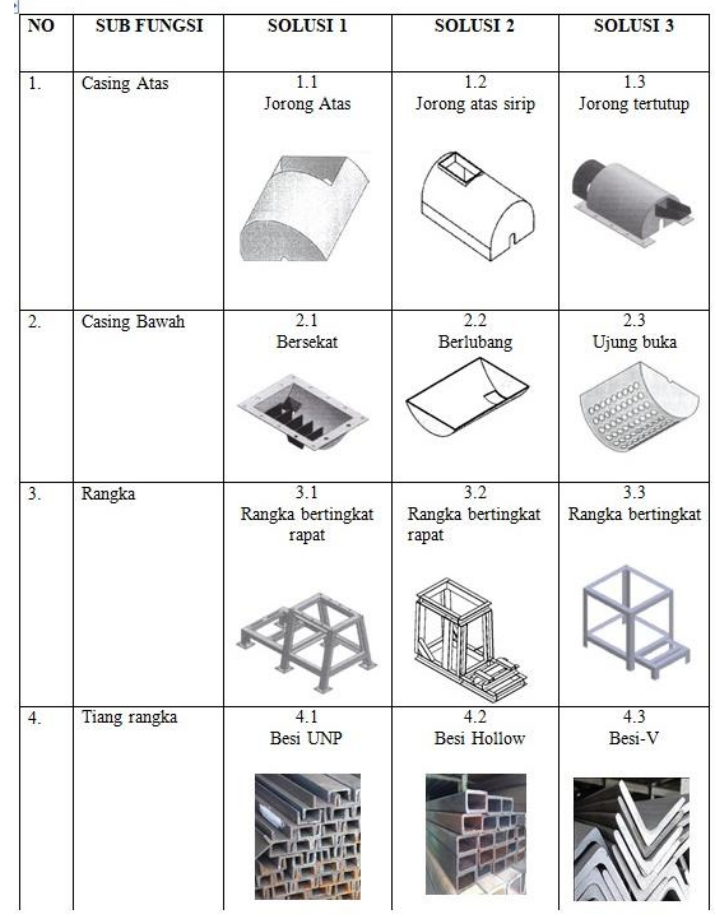

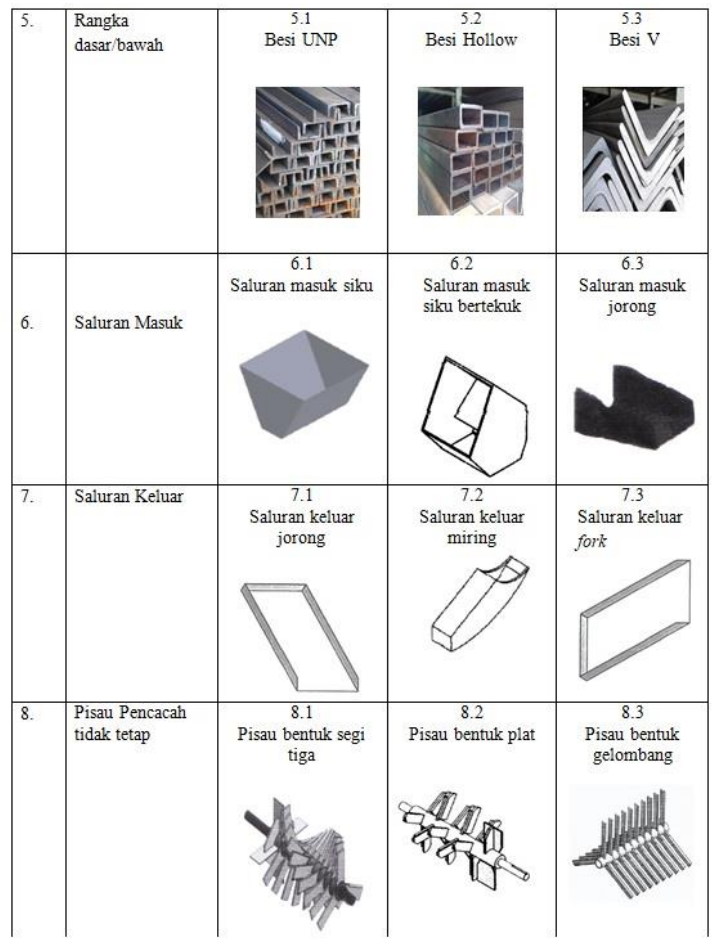

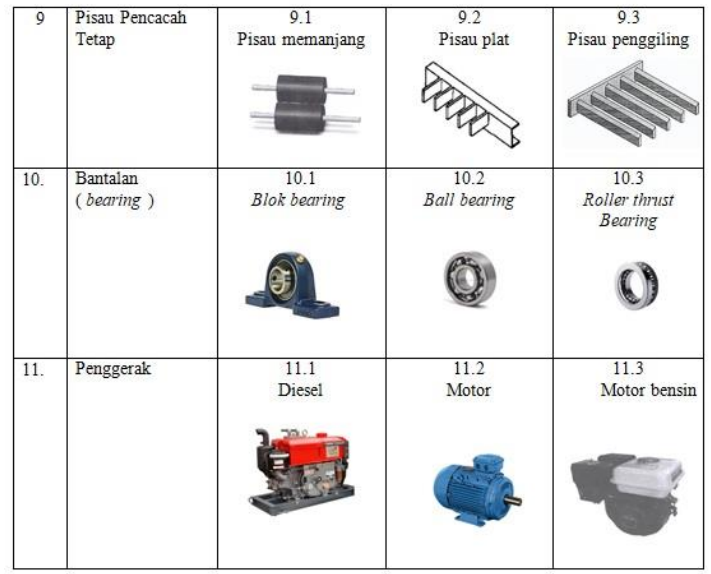

Tabel 4. Pemilihan Kombinasi Prinsip Solusi

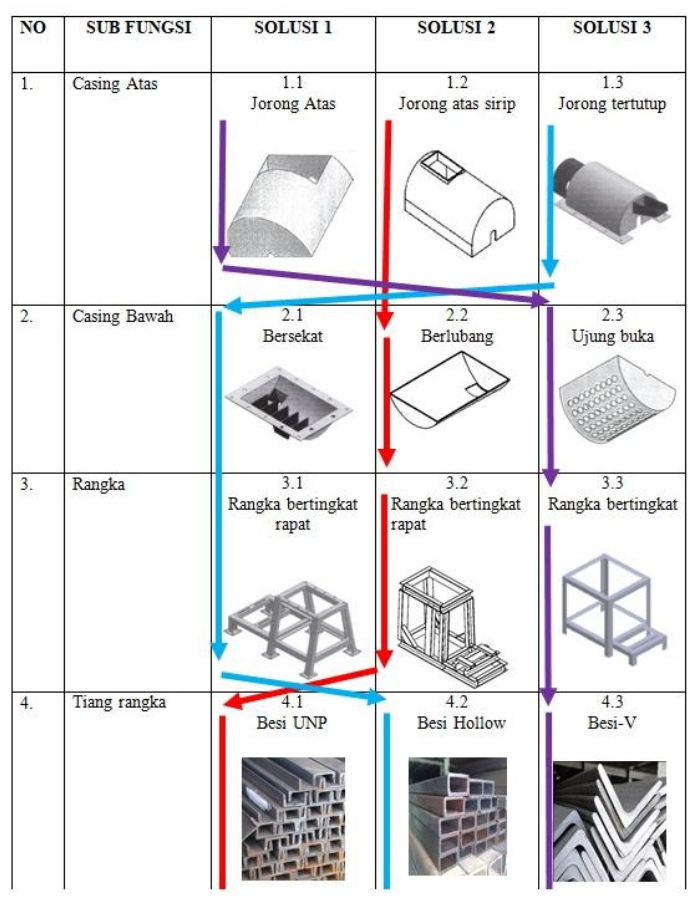



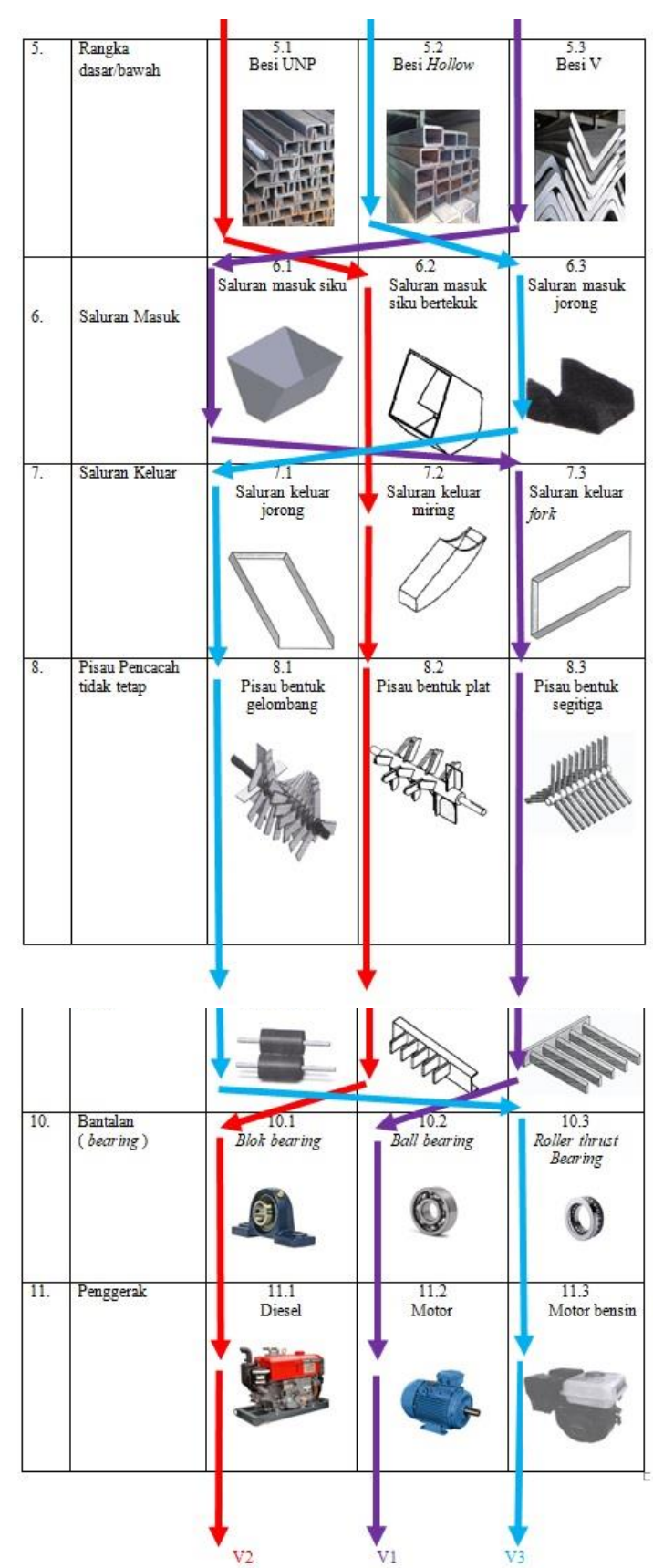

\section{KESIMPULAN}

Dari hasil perancangan desin mesin pencacah pelepah sawit yang dapat disimpulkan sebagai berikut:

1. Dalam penelitian ini dirancang sebuah desain mesin pencacah daun pelepah sawit dengan menggunakan metode DFMA(Design For Manufacture and assembly), Batasan masalahnya hanya pada desain, tetapi tidak menghitung seperti perancangan puli, poros, dan lain-lain dikarenakan ini adalah luaran dari penelitian dosen pemula, yang mana ketuanya dari fakultas pertanian, jadi hanya desai dan hasil rancangan tidak dianalisis.

2. Dari 3 jenis varian yang di pilih dengan menggunakan pendekatan DFMA adalah varian nomor 2 (dua) dengan skor tertinggi yaitu $\underline{\mathbf{7 , 5 7 9}}$.

3. Hasil skor tertinggi lalu sket, kemudian digambar menggunakan software autodesk inventor.

\section{UCAPAN TERIMAKASIH}

Ucapan terimakasih kami sampaikan kepada pihak-pihak yang telah membantu dalam penyusunan artikel ini.

\section{DAFTAR PUSTAKA}

[1] Anizar, Widyastuti Endah, B. Torong, and H. Kus, "Perbaikan Disain Alat Pencacah Pelepah Sawit untuk Mengurangi Keluhan Sakit Peternak Sapi," SNTI dan SATELIT, vol. 2017, pp. 4-6, 2017.

[2] Faizal Ary, S. Lutfianto, and Nurwildani Fajar, "DESAIN PENGEMBANGAN PRODUK WALLSHELF MENGGUNAKAN INTEGRASI QFD DAN DFMA DI UD. XYZ," vol. 15, no. 2, pp. 11-16, 2017.

[3] Hasibuan Yogi Khoiri and R. M. Jabbar, "Rancangan Perbaikan Stopcontact Melalui Pendekatan Metode Dfma (Design for Manufacturing and Assembly) Pada Pt. Xyz," J. Tek. Ind. USU, vol. 1, no. 2, pp. 34-39, 2013.

[4] Hasrin, "RANCANG BANGUN MESIN PEMARUT PELEPAH KELAPA SAWIT UNTUK PAKAN TERNAK," 2013, vol. 27, pp. $38-44$.

[5] Kurnianto Rahmat Rifko;Agung Wibowo; Tri Prakosa, "Penerapan Metoda Design for Manufacture and Assembly pada Handle Transformer Hand Bike," 2015, no. Snttm Xiv, pp. 7-8.

[6] ROBIYANSYAH, "PERANCANGAN MESIN PENCACAH PELEPAH SAWIT UNTUK PAKAN TERNAK SAPI," $J$. $M h s$. Tek. MEsin, 2015.

[7] R. L, Suhariyanto, Widiyono, and Mursid, "Analisa Gaya dan Daya Mesin Pencacah Rumput Gajah Berkapasitas 1350 kg/jam," J. Energi Dan Manufaktur, vol. 7, no. 2, pp. 163172, 2015.

[8] Sularso and K. Suga, Dasar Perencanaan dan Pemilihan Elemen Mesin. 2004.

[9] Sulaiman Fahmi, "Desain Produk : Rancangan Tempat Lilin Multifungsi Dengan Pendekatan 7 Langkah Nigel Cross," Teknovasi, vol. 4, no. 1, pp. 32-41, 2017.

[10] U. Khoirul, "Rancang Bangun Alat Pencacah Sampah Organik Tipe Serut," Repos. Institusi USU, pp. 1-12, 2017.

[11] BPS Rokan Hulu. 2018. Rokan Hulu dalam Angka. BPS Rokan Hulu. Rokan Hulu. 